\title{
Synthesis and characterization of phenylethynylcarbonyl terminated novel thermosetting imide compound
}

\author{
H. Kimura ${ }^{1}$, K. Ohtsuka ${ }^{1}$, A. Matsumoto ${ }^{1}$, H. Fukuoka ${ }^{2}$, Y. Oishi ${ }^{3}$ \\ ${ }^{1}$ Thermosetting Resin Lab., Organic Materials Research Division, Osaka Municipal Technical Research Institute, 1-6-50 \\ Morinomiya, Joto-ku, 536-8553 Osaka, Japan \\ ${ }^{2}$ Research \& Development Division, Mitsubishi Gas Chemical Company, Inc., 2-5-2 Marunouchi, Chiyoda-ku, 100-8324 \\ Tokyo, Japan \\ ${ }^{3}$ Department of Chemistry and Bioengineering, Faculty of Engineering, Iwate University, 3-18-8 Ueda, Morioka, \\ 020-8550 Iwate, Japan
}

Received 17 July 2012; accepted in revised form 22 September 2012

\begin{abstract}
Phenylethynyl terminated novel imide compound based on 1,3-bis(3-aminophenoxy)benzene (APB) and phenylethynyl trimellitic anhydride (PETA) were prepared. The curing behavior of phenylethynyl terminated imide compound was investigated by differential scanning calorimetry and Fourier transform infrared spectrometry. The curing reaction of phenylethynylcarbonyl end group completed at $220^{\circ} \mathrm{C}$, and proceeded much faster than that of phenylethynyl end group. Glass transition temperature of the thermosetting resin from phenylethynylcarbonyl terminated novel imide compound determined by dynamic mechanical analysis was almost the same as that of $o$-cresolnovolac type epoxy resin. In addition, the thermosetting resin from phenylethynylcarbonyl terminated novel imide compound exhibited excellent thermal and dimensional stabilities. These excellent properties of these phenylethynyl terminated imide compound might be due to the incorporation of alkene group or aromatic ring substitutes in the backbones, which might enhance the chain interaction (molecular packing) and reduce the molecular chain mobility.
\end{abstract}

Keywords: thermosetting resins, imide, phenylethynylcarbonyl

\section{Introduction}

Aromatic polyimides are well known as high-performance polymer materials widely used in aerospace and electronics fields. They have some excellent properties such as high thermal stability, good mechanical properties and superior chemical resistance. However, their rigid polymer backbones and the strong chain interactions result in poor solubility and high softening or melting temperature for most of aromatic polyimides, which limit their use for commercial purposes.

Therefore, for molding compounds or matrix resins of fiber reinforced plastics, many addition-type (thermosetting) polyimides (imide oligomers termi- nated with reactive groups) have been developed [1-2]. These imide oligomers terminated with reactive groups could be thermally cured at high temperatures providing good processibility. Namely, due to their oligomeric nature, these materials exhibit excellent processability during fabrication of neat resin moldings and composites under pressure.

The recently best known reactive group among the addition-type polyimides is the phenylethynyl group. The phenylethynyl reactive group has high-cure temperature and a good processing window can be obtained. Upon thermal cure for $\sim 1 \mathrm{~h}$ at $350-370^{\circ} \mathrm{C}$, the phenylethynyl group undergoes a complex reaction involving chain extension, branching and

\footnotetext{
${ }^{*}$ Corresponding author, e-mail: kimura@omtri.or.jp

(C) BME-PT
} 
crosslinking to afford a pseudo three dimensional network. The networks exhibit high thermal stability, good mechanical properties and superior chemical resistance as well as aromatic polyimides [1]. A system based on this, namely, phenylethynyl-terminated imide, PETI-5 shown in Figure 1, has been formulated by the group at the NASA Langley Research Center. The material is a random copolymer prepared from 3,4'-oxydianiline, 1,3-bis(3aminophenoxy)benzene and 3,3',4,4'-biphenyltetracarboxylic dianhydride and end-capped with 4-phenylethynylphthalic anhydride at a calculated number average molecular weight $\left(M_{\mathrm{n}}\right)$ of $5000 \mathrm{~g} / \mathrm{mol}$. This material has displayed good processability and excellent mechanical properties in adhesive and composite forms. The cured PETI-5 has high fracture toughness, high thermo-oxidative stability, and good processability. However, the cured resin has a relatively low $T_{\mathrm{g}}$ of $270^{\circ} \mathrm{C}$ because flexible diamines are introduced for the purpose of high melt fluidity [3].

Yokota and coworkers [4-5] have developed an amorphous, asymmetric, and addition-type polyimide 'TriA-PI' shown in Figure 2. TriA-PI is prepared from asymmetric monomer, 2,3,3',4'-biphenyltetracarboxylic dianhydride (a-BPDA), 4,4'-diaminodiphenyl ether (4,4'-ODA), and PEPA. Both the imide oligomer and cured polymer have irregular and asymmetric structures that are derived from aBPDA, resulting in a low melting temperature and a low melt viscosity for the imide oligomer, and a high $T_{\mathrm{g}}$ value of $343^{\circ} \mathrm{C}$ for the cured polymer. Along with good processability, TriA-PI has high heat resistance, high thermooxidative stability, and good fracture toughness [3].
However, phenylethynyl terminated imide oligomers require high temperature (about $350-370^{\circ} \mathrm{C}$ ) treatment to completely remove solvent and to convert the oligomeric precursor into cured polyimide, which limit their use for commercial all purposes except for the special use of aerospace field.

In this report, we synthesized phenylethynylcarbonyl terminated imide compound and investigated the curing behavior and the properties of the cured thermosetting resin.

The phenylethynylcarbonyl group may be more flexible than the phenylethynyl group because of the adjacent carbonyl group. And, due to the electron withdrawing groups, such as ketone on acetylene bond, phenylethynylcarbonyl group terminated imide compound might enhance the rate of cure. In this way, by the introduction of the carbonyl group adjacent of phenylethynyl group, the high cure temperature (about $350-370^{\circ} \mathrm{C}$ ) of phenylethynyl terminated polyimide could be lowered.

In this study, we investigated the synthesis and characterization of phenylethynylcarbonyl terminated novel thermosetting imide compound. The novel phenylethynylcarbonyl-terminated imide compound has only two imide groups in the molecular structure, and so differs from polyimide resins. And the curing condition of the new imide compound may be completely different from polyimide. The properties of thermosetting resin are influenced by the curing condition, especially maximum curing temperature. Therefore, we think this novel compound as the new thermosetting resin, and compare the new imide compound to an epoxy resin which has almost similar curing condition. We selected higher performance o-cresol novolac type epoxy

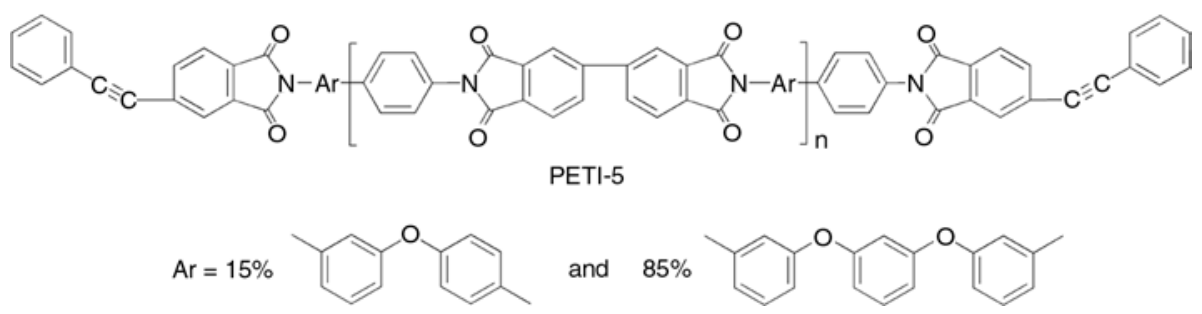

Figure 1. Chemical structure of PETI-5

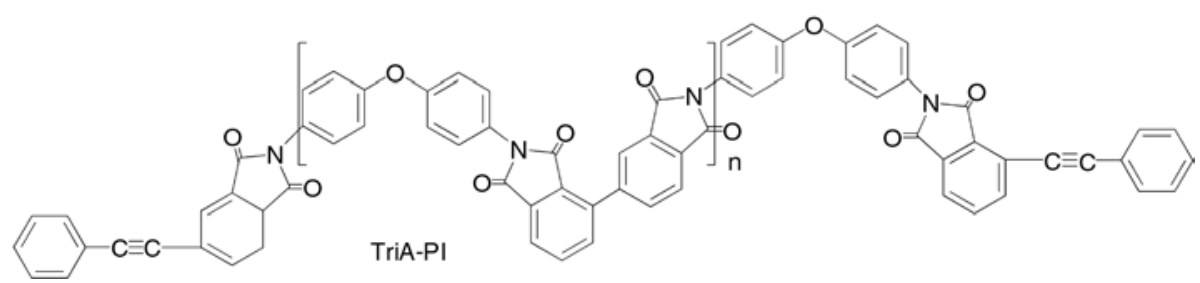

Figure 2. Chemical structure of TriA-PI 
resin which was used as encapsulating material for semiconductors of epoxy resins.

\section{Experimental}

\subsection{Materials}

1,3-bis(3-aminophenoxy)benzene (APB) was supplied by Mitsubishi Gas Chemical Company, Inc. (Tokyo, Japan). Phenylethynyl trimellitic anhydride (PETA) was supplied by Nexam chemical AB (Lund, Sweden). Pyridine, acetic anhydride and Nmethyl-2-pyrrolidone were purchased from Nacalai Tesuque, Inc. (Kyoto, Japan). All chemicals were used without further purification. The chemical structures of APB and PETA are shown in Figure 3. $O$-cresol novolac type epoxy resin (EP, epoxy equivalent, 211) and 2-ethyl-4-methylimidazole as a curing accelerator were supplied by Mitsubishi Chemical Corp. (Tokyo, Japan). Phenol novolac (phenolic hydroxyl equivalent, 94) as a curing agent was<smiles>O=C(C#Cc1ccccc1)c1ccc2c(c1)C(=O)OC2=O</smiles>

PETA<smiles>Nc1cccc(Oc2cccc(Oc3cccc(N)c3)c2)c1</smiles>
APB

Figure 3. Chemical structures of PETA and APB supplied by Asahi Organic Chemicals Industry Co. Ltd. (Tokyo, Japan).

\subsection{Synthesis of phenylethynylcarbonyl terminated imide compound}

The synthesis of phenylethynylcarbonyl terminated imide compound was conducted by chemical imidization method [6-7]. 1,3-bis(3-aminophenoxy) benzene APB (5.84 g, $20 \mathrm{mmol})$ and N-methyl-2pyrrolidone (NMP, $40 \mathrm{ml}$ ) were placed in a three necked flask, equipped with a magnetic stirrer and calcium chloride drying tube. The glass flask was dried or removed from a hot oven to prevent water from interfering with the reaction. Phenylethynyl trimellitic anhydride PETA (11.06 g, $40 \mathrm{mmol}$ ) was added to the solution. The reaction was allowed to stir for $24 \mathrm{~h}$ at room temperature under air. Subsequently, pyridine $(6.32 \mathrm{~g}, 80 \mathrm{mmol})$ and acetic anhydride $(8.16 \mathrm{~g}, 80 \mathrm{mmol})$ was added slowly to the solution; the solution was stirred for $30 \mathrm{~min}$ at room temperature under air. The solution was then poured into water. The product was washed with water, filtered, and then dried at $60^{\circ} \mathrm{C}$ in vacuo. The scheme for synthesis of phenylethynylcarbonyl terminated imide compound (PECI-APB) is shown in Figure 4. The structure of the obtained compound (PECIAPB) was analyzed by ${ }^{1} \mathrm{H}-\mathrm{NMR}$ measurement. ${ }^{1} \mathrm{H}$ NMR measurement was carried out on Japan Electron Company (Tokyo, Japan) JMN-GSX-270 instrument operating at $270 \mathrm{MHz}$. Deuterated dimethyl sulfoxide was used as a solvent and tetramethylsilane was used as an internal standard.

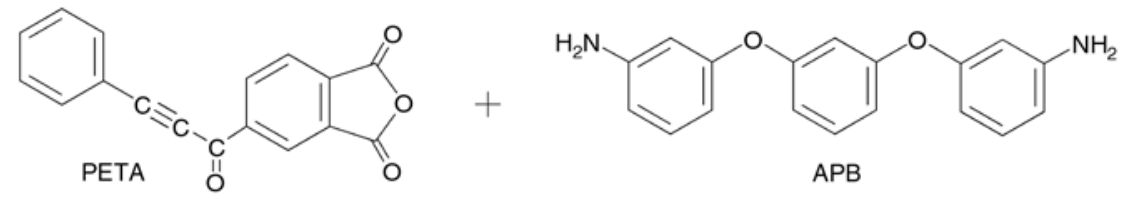

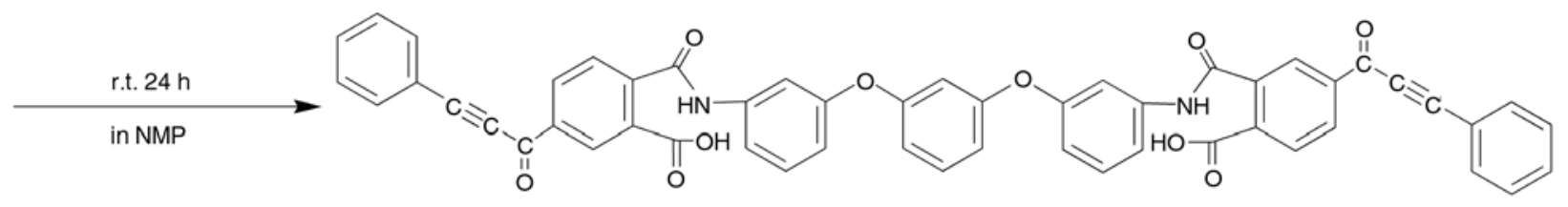<smiles>CC(C)[Pb]NC(=O)c1cccc(Oc2cccc(N3C(=O)c4ccc(C(=O)C#Cc5ccccc5)cc4C3=O)c2)c1</smiles>

Figure 4. Synthesis of phenylethynylcarbonyl terminated imide compound (PECI-APB) 
${ }^{1} \mathrm{H}-\mathrm{NMR}$ (PECI-APB, DMSO-d6, $\delta$ ); 8.60-8.62 ppm (d, 2H, CH), $8.37 \mathrm{ppm}$ (s, 2H, CH), 8.08-8.12 ppm (d, 2H, CH), 7.82-7.88 ppm (d, 4H, CH), 7.10$7.70 \mathrm{ppm}(\mathrm{m}, 15 \mathrm{H}, \mathrm{CH}), 6.85-6.95 \mathrm{ppm}(\mathrm{d}, 2 \mathrm{H}$, $\mathrm{CH}), 6.65-6.82 \mathrm{ppm}(\mathrm{s}, 1 \mathrm{H}, \mathrm{CH})$.

\subsection{Curing condition of phenylethynylcarbonyl terminated imide compound}

Phenylethynylcarbonyl terminated imide compound was cured in a mold using a programmed oven cycle. The curing condition was determined as $200^{\circ} \mathrm{C} / 3 \mathrm{~h}+220^{\circ} \mathrm{C} / 3 \mathrm{~h}$ from the results of differential scanning calorimetry (DSC). The molded sample contained a small amount of voids, but the sample was cut to use the void-free sample for each measurement.

To compare the characteristics of phenylethynylcarbonyl terminated imide compound with other resins, $o$-cresol novolac type epoxy resin, which was used as encapsulating material for semiconductors, was cured in a mold using a programmed oven cycle. Epoxy resin compositions were prepared by uniformly melt mixing the components (o-cresol novolac epoxy resin 211 parts per hundred parts [phr], phenol novolac $94 \mathrm{phr}$, 2-ethyl-4-methylimidazole $2.1 \mathrm{phr}$ ) in a hot twin-roll, followed by cooling and grinding. The curing reaction of epoxy resin was carried out under the same condition as that of the phenylethynylcarbonyl terminated imide compound $\left(200^{\circ} \mathrm{C} / 3 \mathrm{~h}+220^{\circ} \mathrm{C} / 3 \mathrm{~h}\right)$ to evaluate the characteristics.

\subsection{Characterization of phenylethynylcarbonyl terminated imide compound and the cured thermosetting resin}

The structures of phenylethynylcarbonyl terminated imide compound and the cured thermosetting resin were analyzed by Fourier Transform Infrared Spectrophotometer (FT-IR). FT-IR measurement was carried out on Nicolet Impact 420 instrument (Thermo Fisher Scientific K.K, Yokohama, Japan). The spectral range was $4000-400 \mathrm{~cm}^{-1}$. One hundred twenty-eight scans were averaged at a resolution of $4 \mathrm{~cm}^{-1}$. Samples were prepared as $\mathrm{KBr}$ pellets.

FT-IR (PECI-APB, KBr); $1780 \mathrm{~cm}^{-1}$ (s, imide $\mathrm{C}=\mathrm{O}$ asymmetric stretching), $1725 \mathrm{~cm}^{-1}$ (vs, imide $\mathrm{C}=\mathrm{O}$ symmetric stretching), $2213 \mathrm{~cm}^{-1}$ (m, phenylethynyl stretching), $1600 \mathrm{~cm}^{-1}$ (s, aromatic $\mathrm{C}=\mathrm{C}$ ), $1370 \mathrm{~cm}^{-1}$ (s, imide $\mathrm{C}-\mathrm{N}$ stretching), $739 \mathrm{~cm}^{-1}$ (s, imide $\mathrm{C}-\mathrm{N}$ bending).

Differential scanning calorimetry (DSC) was applied to evaluate the cure behavior of phenylethynylcarbonyl terminated imide compound. DSC was measured with heating rate of $10^{\circ} \mathrm{C} / \mathrm{min}$ under $\mathrm{N}_{2}$ atmosphere on a Seiko Instruments Co., Ltd., (Chiba, Japan) STI EXSTAR 6000.

The properties of the cured thermosetting resin were characterized by dynamic mechanical analysis (DMA), thermal gravimetric analysis (TGA) and thermal mechanical analysis (TMA).

Dynamic mechanical analysis (DMA) was applied to evaluate the glass transition temperature $\left(T_{\mathrm{g}}\right)$. Dynamic mechanical analysis was measured by a three points bending method at $1 \mathrm{~Hz}$, amplitude of $10 \mu \mathrm{m}$, with a heating rate of $2^{\circ} \mathrm{C} / \mathrm{min}$ on a Seiko Instruments Co., Ltd (Chiba, Japan). DMS-110 Dynamic Mechanical Analysis Spectrometer. The test specimen consists of $50 \mathrm{~mm}$ long and $15 \mathrm{~mm}$ wide with a thickness of 2-3 $\mathrm{mm}$. The peak temperature of $\tan \delta$ by dynamic mechanical analysis was considered as $T_{\mathrm{g}}[8]$.

Thermal gravimetric analysis (TGA) was applied to evaluate the thermal stability. TGA was measured with heating rate of $10^{\circ} \mathrm{C} / \mathrm{min}$ under $\mathrm{N}_{2}$ atmosphere on a Seiko Instruments Co., Ltd. (Chiba, Japan) TGA 5200 Thermal Gravimetric Analyzer. The values of 5\% mass loss temperature were evaluated.

Thermal mechanical analysis (TMA) was applied to evaluate the dimensional stability. TMA was measured with heating rate of $2^{\circ} \mathrm{C} / \mathrm{min}$ under $\mathrm{N}_{2}$ atmosphere on a Seiko Instruments Co., Ltd. (Chiba, Japan) TMA/SS 6100 Thermal Mechanical Analyzer. The oblong specimen measuring 3-4 $\mathrm{mm}$ in length and usually $10-15 \mathrm{~mm}$ in height was subjected to a loading $5 \mathrm{~g}$ force via a vertically adjustable quartz glass probe. The value of coefficient of thermal expansion $\left(\mathrm{CTE}, 40-60^{\circ} \mathrm{C}\right)$ was evaluated.

\section{Results and discussion}

\subsection{Synthesis of phenylethynylcarbonyl terminated imide compound}

The synthesis of phenylethynylcarbonyl terminated imide compound was conducted by chemical imidization method [6-7]. The formation of poly (amic acid)s is achieved via the reaction of a dianhydride and a diamine in a dry aprotic solvent at room temperature. The reaction mechanism involves 
the nucleophilic attack of the amino group on the carbonyl carbon of the anhydride group, followed by the opening of the anhydride ring to form an amic acid group. The second pathway of cyclodehydration of amic acid to imide involves the use of a chemical dehydrating agent to promote ring closure reactions, which is effective for either soluble or insoluble polyimides. Commonly used reagents include acid anhydrides in dipolar aprotic solvents or in the presence of tertiary amines. Among the dehydrating agent used were acetic anhydride, benzoic anhydride, as well as others. The amine catalysts used include pyridine, N-methylmorpholine, trialkylamines and others. For this work, acetic anhydride and pyridine were used, although other chemical combinations may be equally amenable to this system.

In several instances, the product yield was found to be about $90 \%$. And it was found that phenylethynylcarbonyl terminated imide compound could be easily dissolved in DMSO, to afford a homogeneous solution. But the imide compound was insoluble in other solvents such as acetone, methanol, chloroform, ethyl acetate and tetrahydrofuran.

${ }^{1} \mathrm{H}-\mathrm{NMR}$ spectrum of raw materials (PETA and $\mathrm{APB}$ ) and the product (phenylethynylcarbonyl ter-
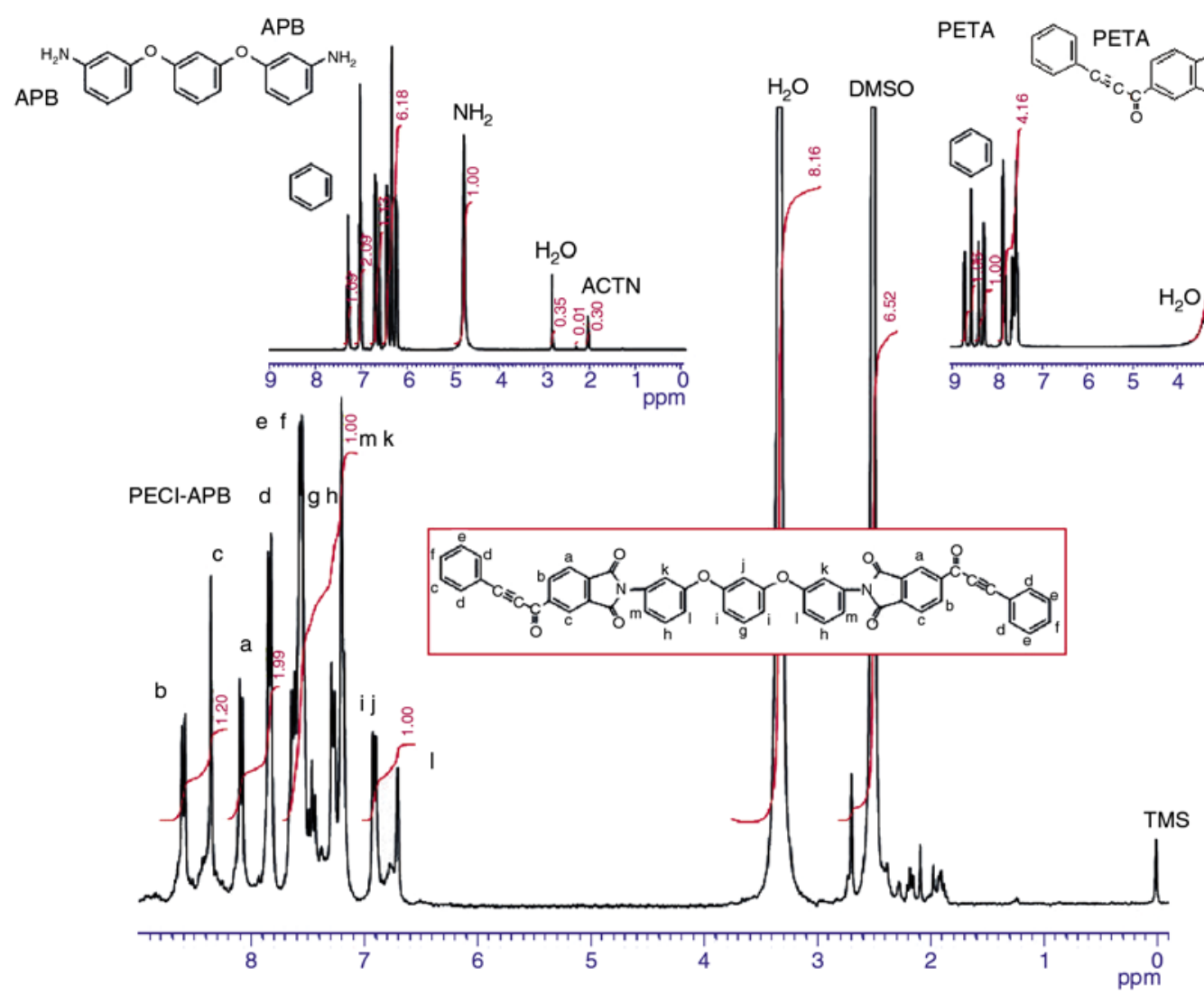

Figure 5. ${ }^{1} \mathrm{H}-\mathrm{NMR}$ spectrum of phenylethynylcarbonyl terminated imide compound (PECI-APB) in DMSO-d6 minated imide compound, PECI-APB) is shown in Figure 5. As a result, a peak (z, $4.78 \mathrm{ppm})$ assigned to the primary amine groups of APB were not detected. All peaks assigned to the aromatic ring proton were detected. The structure of phenylethynylcarbonyl terminated imide compound (PECI-APB) was confirmed by NMR. The small peaks at 2.1, 2.3 and $2.7 \mathrm{ppm}$ come from acetic anhydride and $\mathrm{N}-$ metyl-2-pyrrolidone used as the raw material or reaction solvent. And the peak at $2.2 \mathrm{ppm}$ comes from acetic acid arising from acetic anhydride. The peak at $3.4 \mathrm{ppm}$ comes from water used for purification after synthesis of phenylethynylcarbonyl terminated imide compound. There was not significant indication of side reaction in the NMR, and the purity of PECI-APB was almost $100 \%$ from ${ }^{1} \mathrm{H}$ NMR.

The FT-IR spectra of raw materials (PETA and APB), phenylethynylcarbonyl terminated amic acid and phenylethynylcarbonyl terminated imide compound (PECI-APB) are shown in Figure 6.

In Figure 6c, it can be seen that the amic acid compound exhibited the characteristic absorption near $2900-3200 \mathrm{~cm}^{-1}$, which was attributed to COO-H and $\mathrm{HN}-\mathrm{H}$. The absorption at ca. $1710 \mathrm{~cm}^{-1}$, which was related to amic acid $\mathrm{C}=\mathrm{O}(\mathrm{COOH})$ was observed.

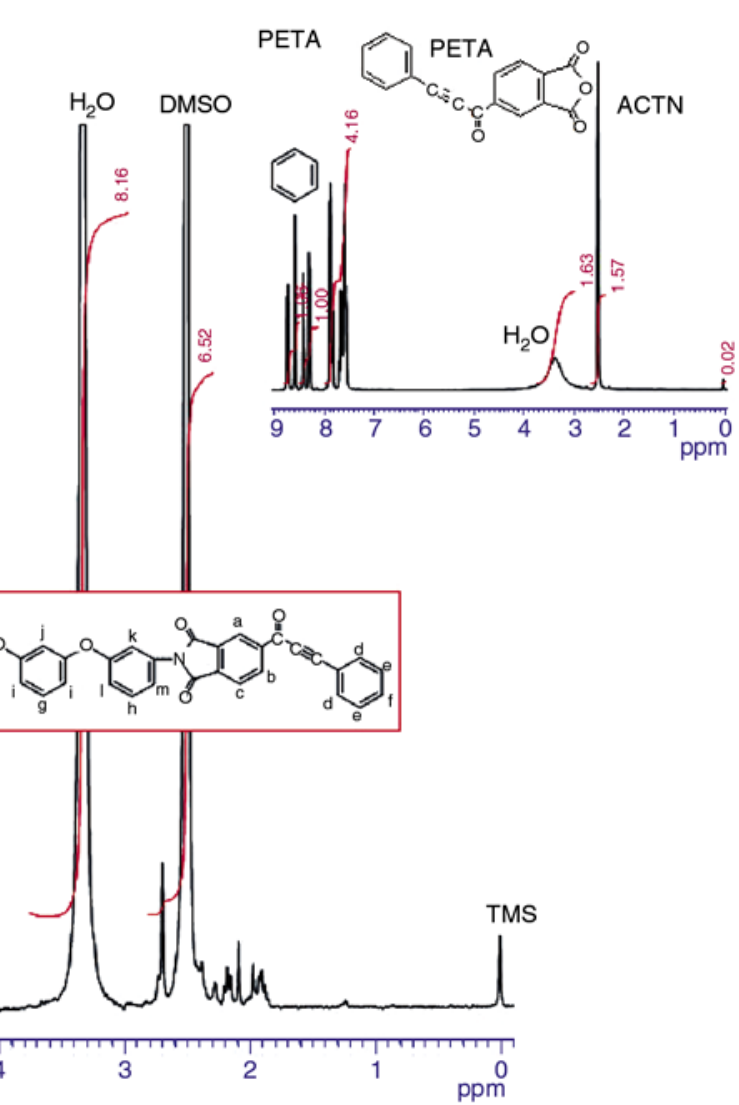




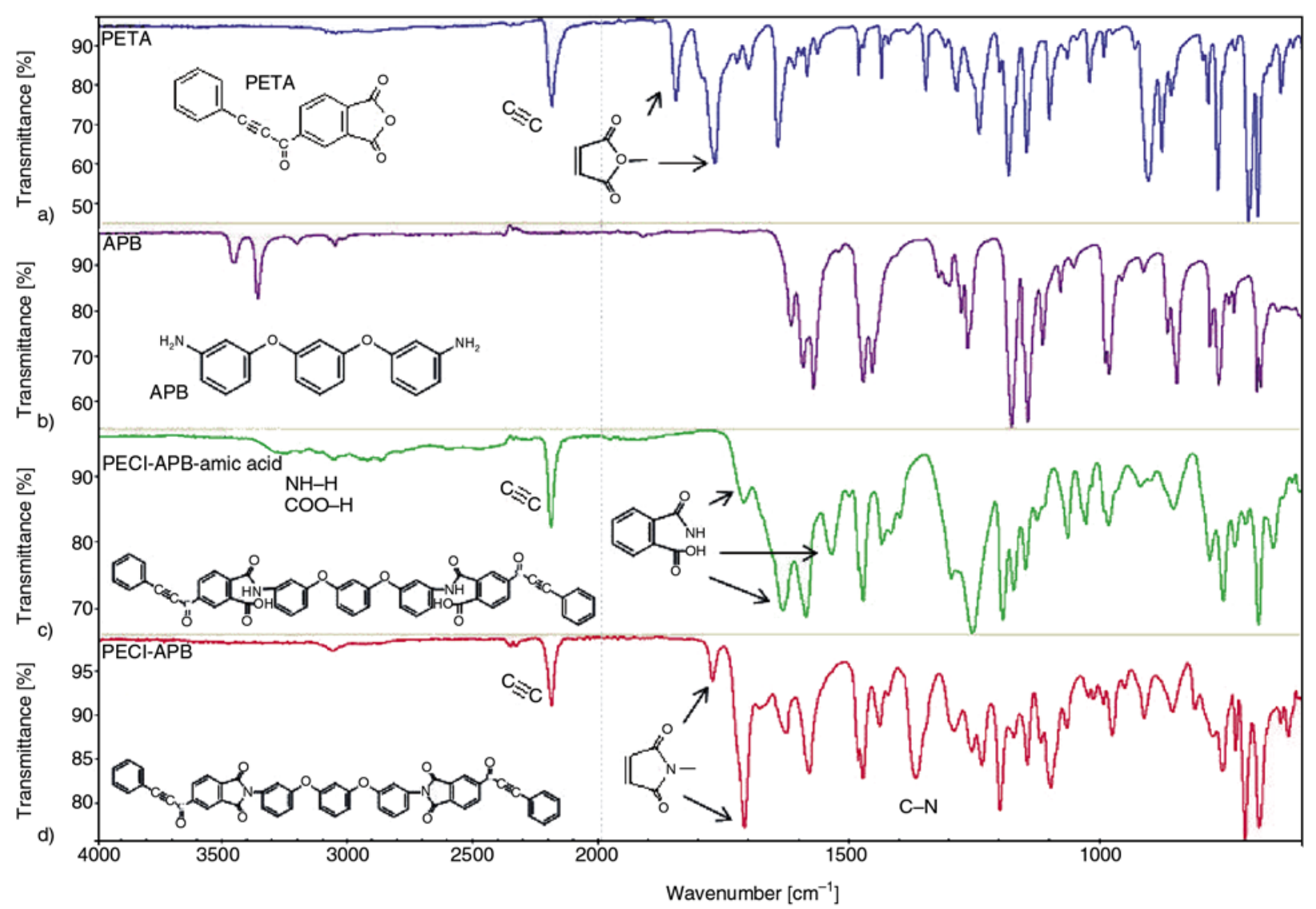

Figure 6. FT-IR spectra of (a) PETA, (b) APB, (c) phenylethynylcarbonyl terminated amic acid and (d) phenylethynylcarbonyl terminated imide compound (PECI-APB)

The absorptions at ca. 1660 and $1550 \mathrm{~cm}^{-1}$, which were related to amide groups of amic acid $\mathrm{C}=\mathrm{O}$ (amide $\mathrm{CONH}$ ) and $\mathrm{C}-\mathrm{NH}$, were also observed.

In Figure 6d, it can be seen that the imide compound exhibited the characteristic absorption around $2213 \mathrm{~cm}^{-1}$, which was attributed to the stretching vibration of ethynyl $\mathrm{C} \equiv \mathrm{C}$. The absorptions at ca. 1780 and $1725 \mathrm{~cm}^{-1}$, which were related to the asymmetric and symmetric stretching vibrations of imide $\mathrm{C}=\mathrm{O}$, were also observed. Moreover, the absorptions around $1600 \mathrm{~cm}^{-1}$ (aromatic $\mathrm{C}=\mathrm{C}$ ), $1370 \mathrm{~cm}^{-1}$ (imide $\mathrm{C}-\mathrm{N}$ ), were also detected. Additionally, the lack of near $2900-3200 \mathrm{~cm}^{-1}$ which was attributed to $\mathrm{COO}-\mathrm{H}$ and $\mathrm{HN}-\mathrm{H}$, the absorption at ca. $1710 \mathrm{~cm}^{-1}$ which was related to amic acid $\mathrm{C}=\mathrm{O}$ $(\mathrm{COOH})$ and the absorptions at ca. 1660 and $1550 \mathrm{~cm}^{-1}$ which were related to amide groups of amic acid $\mathrm{C}=\mathrm{O}$ (amide $\mathrm{CONH}$ ) and $\mathrm{C}-\mathrm{NH}$ indicated that the polyimide did not contain significant amounts of amic-acid functional groups.

By these results of NMR and FT-IR, it was found that the synthesis of phenylethynylcarbonyl terminated imide compound by chemical imidization method was conducted effectively, and the objective phenylethynylcarbonyl terminated imide compound (PECI-APB) was obtained.

\subsection{DSC analysis of phenylethynylcarbonyl terminated imide compound}

DSC thermogram of phenylethynylcarbonyl terminated imide compound (PECI-APB) is shown in Figure 7. From the first DSC heating scan, it is found that phenylethynylcarbonyl terminated imide compound exhibited a weak glass transition around $156^{\circ} \mathrm{C}$ and a broad exothermic peak with the onset and maximum around 180 and $212^{\circ} \mathrm{C}$, respectively. The exothermic peak is assigned to the curing reaction of the phenylethynyl groups, which is accompanied with heat release. As a result, it was found that phenylethynylcarbonyl terminated imide group could react more rapidly than phenylethynyl terminated imide group which needed the high cure temperature (about $350-370^{\circ} \mathrm{C}$ ) [1]. This is because the phenylethynylcarbonyl group might be more flexible than the phenylethynyl group because of the adjacent carbonyl group, and electron withdrawing 


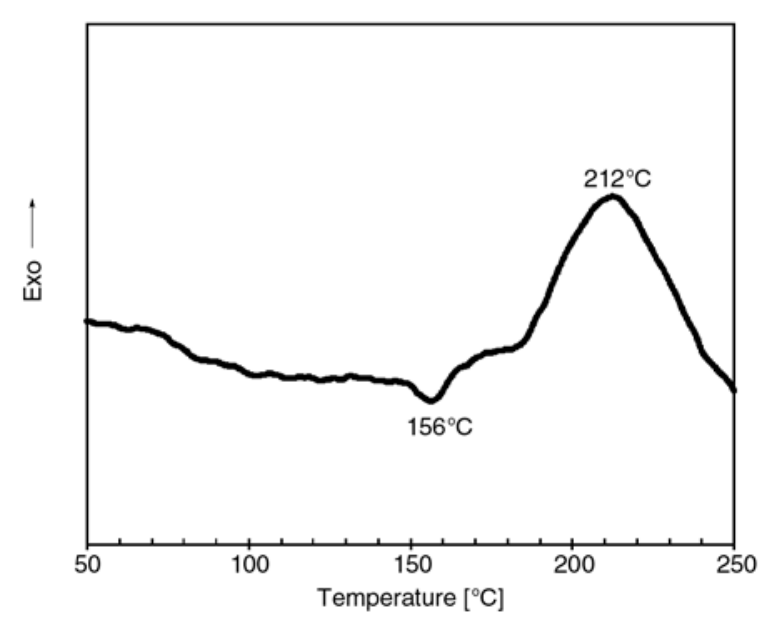

Figure 7. DSC curve of phenylethynylcarbonyl terminated imide compound (PECI-APB)

groups such as ketone on acetylene bond; phenylethynyl group terminated imide compound might enhance the rate of cure.

From the result of DSC measurement, the curing condition was determined as follows: after phenylethynylcarbonyl terminated imide compound (PECIAPB) softened at $160^{\circ} \mathrm{C}$ to remove any bubbles containing in it sufficiently, curing reaction was carried out at $200^{\circ} \mathrm{C} / 3 \mathrm{hr}$. Finally, at $220^{\circ} \mathrm{C} / 3 \mathrm{hr}$ the cured thermosetting resin was postcured so that the curing reaction could proceed completely. In this way, the curing condition of phenylethynylcarbonyl terminated imide compound was determined as $200^{\circ} \mathrm{C} / 3 \mathrm{hr}+220^{\circ} \mathrm{C} / 3 \mathrm{hr}$.

DSC thermogram of the cured resin from phenylethynylcarbonyl terminated imide compound (PECIAPB) is shown in Figure 8. DSC curve of the cured resin showed no exothermic peaks, implying that PECI-APB resin had been completely cured. And

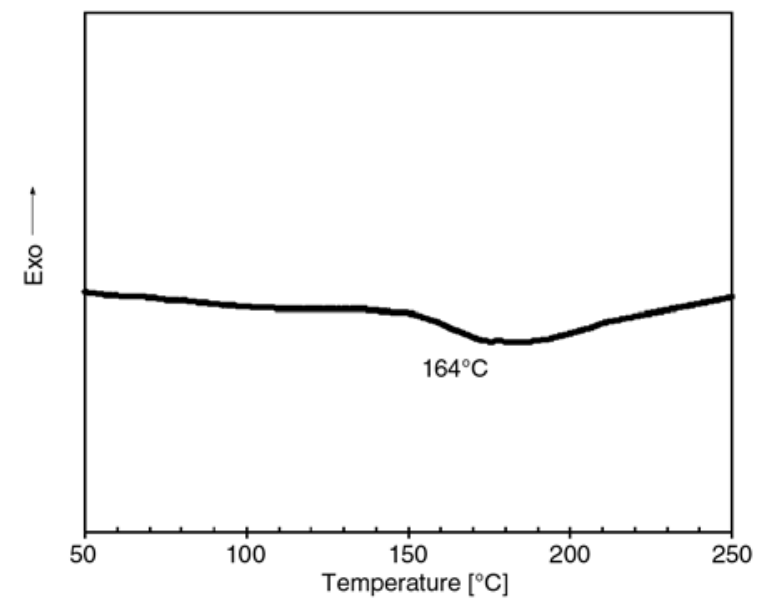

Figure 8. DSC curve of the cured resin from phenylethynylcarbonyl terminated imide compound (PECIAPB) glass transition temperature of the cured resin was observed around $164^{\circ} \mathrm{C}$.

\subsection{Curing reaction of phenylethynylcarbonyl terminated imide compound}

To investigate the curing reaction of phenylethynylcarbonyl terminated imide compound, FT-IR measurement was carried out. FT-IR spectra of the compound before and after the curing reaction of phenylethynylcarbonyl terminated imide compound (PECI-APB) are shown in Figure 9. As a result, the characteristic absorption around $2213 \mathrm{~cm}^{-1}$, which was attributed to the stretching vibration of ethynyl $\mathrm{C} \equiv \mathrm{C}$, disappeared after curing reaction (Figure 9b). The absorptions at ca. 1780 and $1725 \mathrm{~cm}^{-1}$, which were related to the asymmetric and symmetric stretching vibrations of imide $\mathrm{C}=\mathrm{O}$, were also observed. Moreover, the absorptions around $1600 \mathrm{~cm}^{-1}$ (aromatic $\mathrm{C}=\mathrm{C}$ ), $1370 \mathrm{~cm}^{-1}$ (imide $\mathrm{C}-\mathrm{N}$ ), were also detected.

The new absorption of alkene $\mathrm{C}=\mathrm{C}$ at $1635 \mathrm{~cm}^{-1}$ appeared after curing reaction (Figure 9b). It was found that the curing reaction of phenylethynylcarbonyl terminated imide compound occurred, and then the alkene groups or aromatic groups (the absorptions around $1600 \mathrm{~cm}^{-1}$ ) might be generated by the curing reaction.

Based on the investigations on the thermal curing of phenylethynyl terminated imide oligomers it has been suggested that a polyene initially began to form in the curing reaction, which then participated in more complex reactions to yield crosslinked aromatic structures and condensed polycyclic unsaturated structures [9-13].

\subsection{TGA analysis of phenylethynylcarbonyl terminated imide compound}

Figure 10 shows the TGA curves of the cured thermosetting resin from phenylethynylcarbonyl terminated imide compound (PECI-APB) and that from $o$-cresol novolac type epoxy resin (EP). As for phenylethynylcarbonyl terminated imide compound, the initial decomposition temperature, defined as the temperature at which $5 \mathrm{wt} \%$ mass loss occurred, was $432^{\circ} \mathrm{C}$. And the cured resin achieved char yields above $75 \%$ under nitrogen at $600^{\circ} \mathrm{C}$, which exhibited the cured thermosetting resin had good thermal stability. In contrast, the decomposition temperature and the char yield at $600^{\circ} \mathrm{C}$ of epoxy resin was $384^{\circ} \mathrm{C}$ and $37 \%$ respectively (Table 1 ). As a result, 


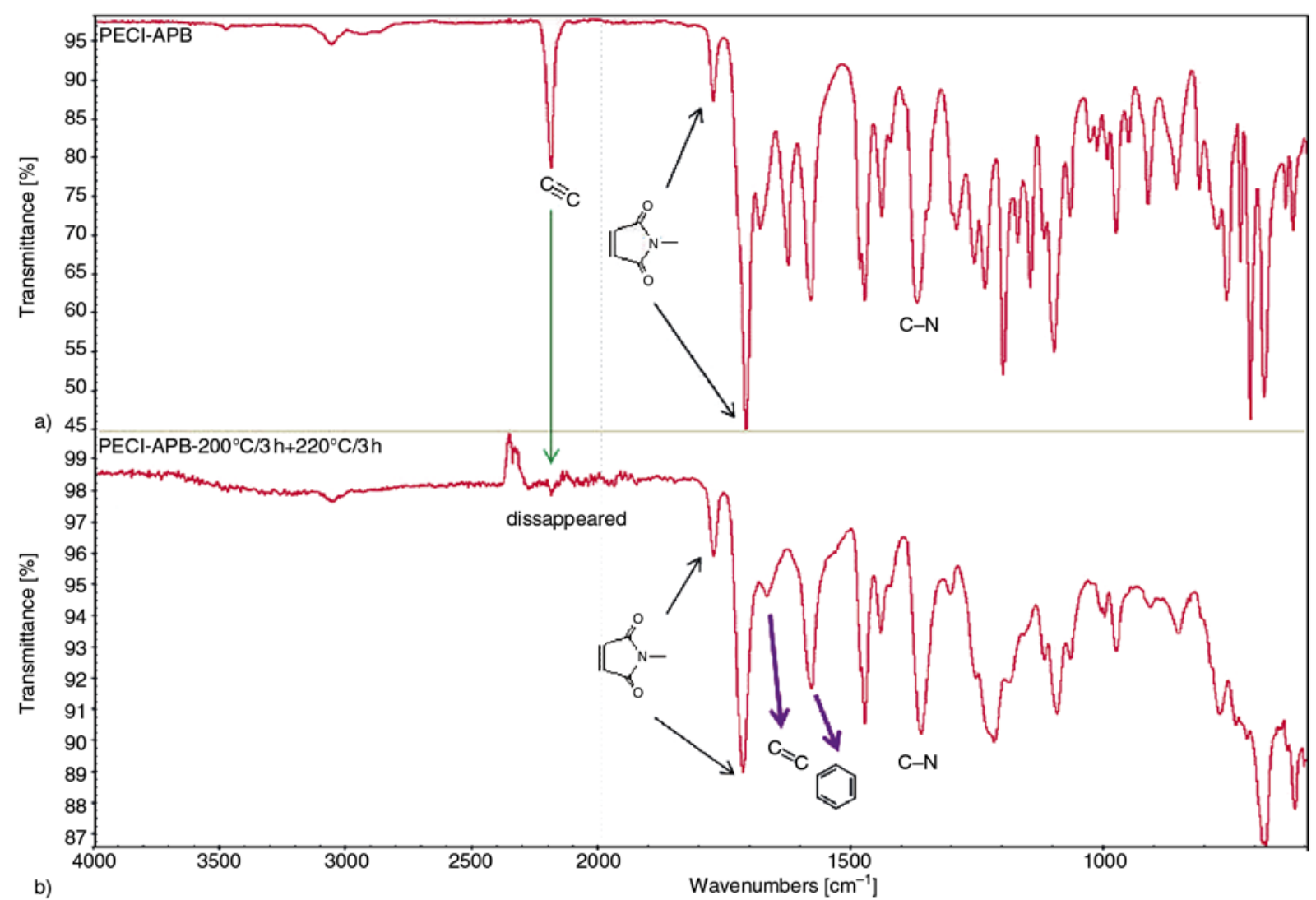

Figure 9. FT-IR spectra of (a) before, (b) after curing reaction of phenylethynylcarbonyl terminated imide compound (PECI-APB)

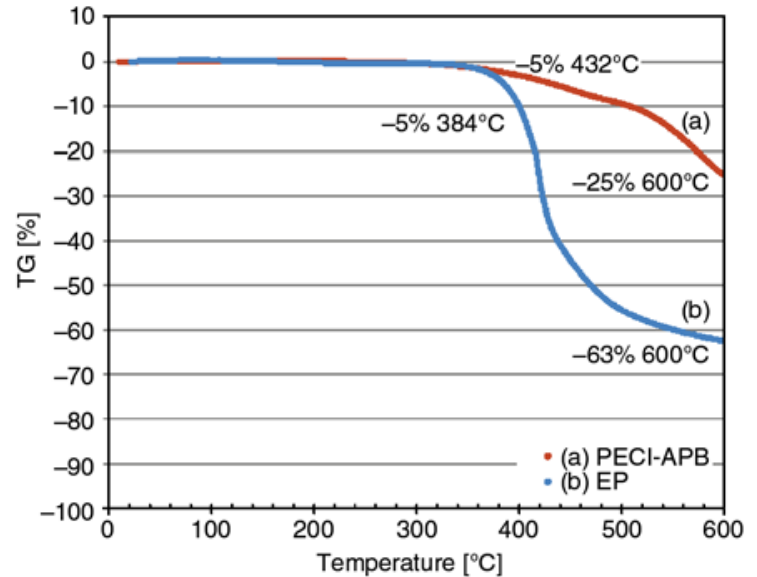

Figure 10. TGA curves of (a) phenylethynylcarbonyl terminated imide compound (PECI-APB) and (b) epoxy resin (EP)

the thermosetting resin from phenylethynylcarbonyl terminated imide compound showed more superior thermal stability to that of epoxy resin. The improvement of thermal stability is due to the incorporation of alkene group or aromatic ring substitutes in the backbones, which might enhance the chain interaction and reduce the molecular chain mobility.
Table 1. Properties of the cured thermosetting resins

\begin{tabular}{|l|c|c|c|c|c|}
\hline \multicolumn{1}{|c|}{ Sample } & $\begin{array}{c}\mathbf{T}_{\mathbf{g}}{ }^{\mathbf{a}} \\
{\left[{ }^{\circ} \mathbf{C}\right]}\end{array}$ & $\begin{array}{c}\mathbf{T}_{\mathbf{d}}{ }^{\mathbf{b}} \\
{\left[{ }^{\circ} \mathbf{C}\right]}\end{array}$ & $\begin{array}{c}\mathbf{C h a r}_{\mathbf{y}} \mathbf{y i e l d} \mathbf{d}^{\mathbf{c}} \\
{[\mathbf{\%}]}\end{array}$ & $\begin{array}{c}\mathbf{\rho}\left(\mathbf{E}^{\prime}\right) \\
{\left[\mathbf{m o l} / \mathbf{m}^{3}\right]}\end{array}$ & $\begin{array}{c}\mathbf{C T E}^{\mathbf{d}} \\
{\left[\mathbf{p p m} /{ }^{\circ} \mathbf{C}\right]}\end{array}$ \\
\hline PECI-APB & 201 & 432 & 75 & $1.5 \cdot 10^{2}$ & 44 \\
\hline Epoxy resin & 205 & 384 & 37 & $1.6 \cdot 10^{4}$ & 57 \\
\hline PETI-5 & 270 & 503 & - & - & - \\
\hline
\end{tabular}

aPeak temp. of $\tan \delta$ by DMA.

${ }^{\mathrm{b}}$ Temperature at which $5 \mathrm{wt} \%$ mass loss occurred.

${ }^{\mathrm{c}}$ At $600^{\circ} \mathrm{C}$.

${ }^{\mathrm{d}}$ The value $\left(40-60^{\circ} \mathrm{C}\right)$ by TMA.

And 5\% decomposition temperature of other imide oligomer (PETI-5) [14] was also shown in Table 1. The thermosetting resin from phenylethynylcarbonyl terminated imide compound showed lower thermal stability to other imide oligomer (PETI-5).

\subsection{DMA analysis of phenylethynylcarbonyl terminated imide compound}

The curves of Dynamic Mechanical Analysis (DMA) are shown in Figure 11. As a result, glass transition temperature $\left(T_{\mathrm{g}}\right)$ of the thermosetting resin from phenylethynylcarbonyl terminated imide compound (PECI-APB) was $201^{\circ} \mathrm{C}$. And $T_{\mathrm{g}}$ of the cured epoxy resin (EP) was $205^{\circ} \mathrm{C}$ (Table 1 ). 


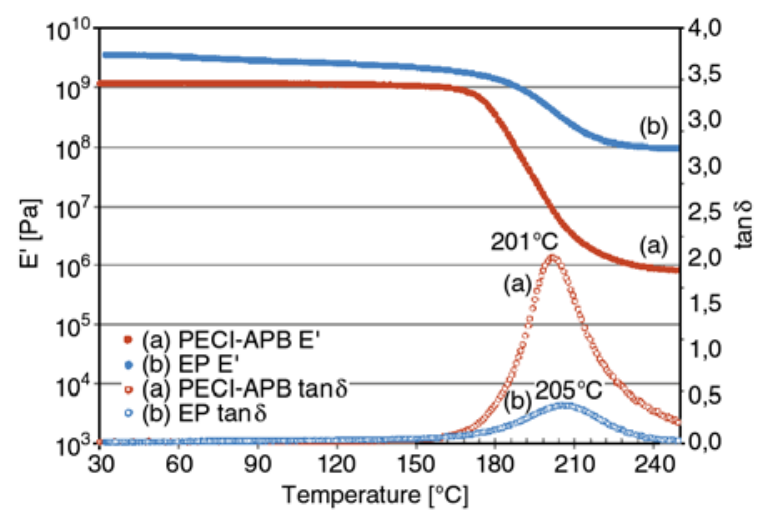

Figure 11. DMA curves of (a) phenylethynylcarbonyl terminated imide compound (PECI-APB) and (b) epoxy resin (EP)

The crosslink density $\rho\left(E^{\prime}\right)$ can be calculated using the equation of state for rubbery elasticity (see Equation (1)) [15]:

$\rho\left(E^{\prime}\right)=\frac{E^{\prime}}{3 \Phi R T}$

where $\Phi$ is the front factor, $T$ is the absolute temperature, $R$ is the gas constant, and $E^{\prime}$ is the storage modulus of the sample at temperature $T$. This equation is applicable to polymer networks that have a rubbery plateau region [15]. Though the adoption of this equation to the highly crosslinked system is beyond the applicability of the rubber elasticity theory, there is no theoretical equation to calculate crosslink density for highly crosslinked polymers. Therefore, in our study, the value of $\rho\left(E^{\prime}\right)$ of the samples was calculated at $T_{\mathrm{g}}+40^{\circ} \mathrm{C}$ according to this equation to compare the crosslink density of each sample [16-17]. The results are shown in Table 1, under the assumption that $\Phi$ is equal to 1 [18]. The value of $\rho\left(E^{\prime}\right)$ of the cured resins from phenylethynylcarbonyl terminated imide compound (PECI-APB) was much smaller (one hundredth) than that of the cured epoxy resin (EP). As a result, the thermosetting resin from phenylethynylcarbonyl terminated imide compound showed almost the same $T_{\mathrm{g}}$ as that of epoxy resin. The reason of the good heat resistance of phenylethynylcarbonyl terminated imide compound is due not to high crosslink density, but to the incorporation of alkene group or aromatic ring substitutes in the backbones, which might enhance the chain interaction and reduce the molecular chain mobility. Namely, contrasting the chemical composition of epoxy resin to phenylethynylcarbonyl terminated imide compound, the epoxy does not have the functionalities that are reducing chain mobility.

And $T_{\mathrm{g}}$ of other imide oligomer (PETI-5) [14] was also shown in Table 1 . The thermosetting resin from phenylethynylcarbonyl terminated imide compound showed lower glass transition temperature to other imide oligomer (PETI-5).

\subsection{TMA analysis of phenylethynylcarbonyl terminated imide compound}

The coefficient of thermal expansion (CTE, 40$60^{\circ} \mathrm{C}$ ) of the thermosetting resin from phenylethynylcarbonyl terminated imide compound (PECI-APB) was evaluated by Thermal Mechanical Analysis (TMA). The CTE is another important property with regard to the electronic package applications. Unfortunately, most organic polymers have much higher CTEs (about $40-200 \mathrm{ppm} /{ }^{\circ} \mathrm{C}$ ) than those of the inorganic substrates (for example, fused silica $0.55 \mathrm{ppm} /{ }^{\circ} \mathrm{C}$ ) and conductors (for example, copper $17-20 \mathrm{ppm} /{ }^{\circ} \mathrm{C}$ ) used in electronics. Additionally, CTE of the printed circuit board is $13-18 \mathrm{ppm} /{ }^{\circ} \mathrm{C}$, 80 to $90 \mathrm{ppm} /{ }^{\circ} \mathrm{C}$ in the plate thickness Z-axis direction. This CTE mismatch results in residual stress buildup in the electronic materials following thermal processing. It is of interest to determine the CTEs of the thermosetting resin from phenylethynylcarbonyl terminated imide compound.

As a result, CTE of the thermosetting resin from phenylethynylcarbonyl terminated imide compound (PECI-APB) was $44 \mathrm{ppm} /{ }^{\circ} \mathrm{C}$, which showed relatively lower CTE values. In contrast, CTE of the cured epoxy resin was $57 \mathrm{ppm} /{ }^{\circ} \mathrm{C}$ (Table 1). As a result, the thermosetting resin from phenylethynylcarbonyl terminated imide compound showed much lower coefficient of thermal expansion than that of epoxy resin. The improvement of CTE might be due to the incorporation of alkene group or aromatic ring substitutes in the backbones, which might enhance the chain interaction (molecular packing) and reduce the molecular chain mobility. Namely, the reduction in CTE may be attributed to the segmental motions of the chains that are restricted. Phenylethynylcarbonyl terminated imide compound showed lower CTE than epoxy resin, even though the $T_{\mathrm{g}}$ of epoxy resin was a little higher than that of phenylethynylcarbonyl terminated imide compound. It seems that the chain structure of phenylethynylcarbonyl terminated imide compound which 
has more planar shape than epoxy resin affected the CTE more than the glass transition temperature of the polymer [19].

\section{Conclusions}

In this study, we investigated the synthesis and characterization of phenylethynylcarbonyl terminated novel thermosetting imide compound. As a result, it was found that the curing reaction of phenylethynylcarbonyl terminated imide group proceeded much faster than that of phenylethynyl terminated imide group. This is due to the phenylethynylcarbonyl group might be more flexible than the phenylethynyl group because of the adjacent carbonyl group, and electron withdrawing groups such as ketone on acetylene bond might enhance the rate of cure. From the results of Fourier transform infrared spectrometry measurement, the new absorption of alkene groups $(\mathrm{C}=\mathrm{C})$ at $1635 \mathrm{~cm}^{-1}$ and aromatic groups at $1600 \mathrm{~cm}^{-1}$ appeared after curing reaction. It was found that the curing reaction of phenylethynylcarbonyl terminated imide compound occurred, and then the alkene groups or aromatic groups might be generated by the curing reaction. The cured thermosetting resin from phenylethynylcarbonyl terminated imide compound exhibited had good thermal decomposition stability. From the results of dynamic mechanical analysis and thermal mechanical analysis, the thermosetting resin from phenylethynylcarbonyl terminated imide compound showed almost the same $T_{\mathrm{g}}$ as that of epoxy resin, and the coefficient of thermal expansion of the thermosetting resin from phenylethynylcarbonyl terminated imide compound was $44 \mathrm{ppm} /{ }^{\circ} \mathrm{C}$, which showed relatively lower CTE values. The improvement of these excellent thermal properties might be due to the incorporation of alkene group or aromatic ring substitutes in the backbones, which might enhance the chain interaction and reduce the molecular chain mobility. These excellent properties of the phenylethynyl terminated imide compound demonstrate a promising potential for future use of commercial all purposes except for the special use of aerospace field.

\section{References}

[1] Connell J. W., Smith J. G. Jr., Hergenrother P. M.: Oligomers and polymers containing phenylethynyl groups. Journal of Macromolecular Science Part C: Polymer Reviews, 40, 207-230 (2000). DOI: $10.1081 / \mathrm{MC}-100100585$

[2] Hergenrother P. M.: The use, design, synthesis, and properties of high performance/high temperature polymers: An overview. High Performance Polymers, 15, 3-45 (2003). DOI: $10.1177 / 095400830301500101$

[3] Ishida Y., Ogasawara T., Yokota R.: Development of highly soluble addition-type imide oligomer and polyimide/carbon fiber composite prepared by imide solution prepreg. in ' $16^{\text {th }}$ International Conference on Composite Materials, Kyoto, Japan’ p4 (2007).

[4] Yokota R., Yamamoto S., Yano S., Sawaguchi T., Hasegawa M., Ozawa H., Sato R.: Molecular design of heat resistant polyimides having excellent processability and high glass transition temperature. High Performance Polymers, 13, S61-S72 (2001).

DOI: $10.1088 / 0954-0083 / 13 / 2 / 306$

[5] Ogasawara T., Ishikawa T., Yokota R., Ozawa H., Taguchi M., Sato R., Shigenari Y., Miyagawa K.: Processing and properties of carbon fiber reinforced triple-A polyimide (tri-A PI) matrix composites. Advanced Composite Materials, 11, 277-286 (2002) DOI: 10.1163/156855102762506317

[6] Volksen W.: Condensation polyimides: Synthesis, solution behavior, and imidization characteristics. Advances in Polymer Science, 117, 111-164 (1994). DOI: $10.1007 / \mathrm{BFb} 0021198$

[7] Kailani M. H., Sung C. S. P.: Chemical imidization study by spectroscopic techniques. 1. model amic acids. Macromolecules, 31, 5771-5778 (1998)

DOI: $10.1021 / \mathrm{ma980095d}$

[8] Kwei K. T.: Viscoelasticity of crosslinked epoxy polymer in the transition region. Journal of Polymer Science A2: Polymer Physics, 4, 943-949 (1966). DOI: $10.1002 /$ pol.1966.160040609

[9] Sun H., Huo H., Nie H., Yang S., Fan L.: Phenylethynyl terminated oligoimides derived from $3,3^{\prime}, 4,4^{\prime}$ diphenylsulfonetetracarboxylic dianhydride and their adhesive properties. European Polymer Journal, 45, 1169-1178 (2009).

DOI: $10.1016 /$ j.eurpolymj.2009.01.004

[10] Fang X. M., Rogers D. F., Scola D. A., Stevens M. P.: A study of the thermal cure of a phenylethynyl-terminated imide model compound and a phenylethynyl-terminated imide oligomer (PETI-5). Journal of Polymer Science Part A: Polymer Chemistry, 36, 461-470 (1998).

DOI: 10.1002/(SICI)1099-0518(199802)36:3<461:: AID-POLA10>3.0.CO;2-L 
[11] Nakamura K., Ando S., Takeichi T.: Thermal analysis and sof Thermal analysis and solid lid-state ${ }^{13} \mathrm{C}$ NMR study of crosslink in polyimides containing acetylene groups in the main chain. Polymer, 42, 4045-4054 (2001).

DOI: $10.1016 / \mathrm{S} 0032-3861(00) 00827-2$

[12] Holland T. V., Glass T. E., McGrath J. E.: Investigation of the thermal curing chemistry of the phenylethynyl group using a model aryl ether imide. Polymer, 41, 4965-4990 (2000).

DOI: 10.1016/S0032-3861(99)00578-9

[13] Takekoshi T., Terry J. M.: High-temperature thermoset polyimides containing disubstituted acetylene end groups. Polymer, 35, 4874-4880 (1994). DOI: 10.1016/0032-3861(94)90746-3

[14] Smith Jr. J. G., Connell J. W., Hergenrother P. M.: The effect of molecular weight on the composite properties of cured phenylethynyl terminated imide oligomers. NASA Langley Research Center, Technical Report (1998).

[15] Murayama T., Bell P. J.: Relation between the network structure and dynamic mechanical properties of a typical amine-cured epoxy polymer. Journal of Polymer Science Part A2: Polymer Physics, 8, 437-445 (1970). DOI: $10.1002 /$ pol.1970.160080309
[16] Hasegawa K., Fukuda A., Tonogai S.: Structure and viscoelastic properties of epoxy resins prepared from four-nuclei novolacs. Journal of Applied Polymer Science, 37, 3423-3435 (1989). DOI: $10.1002 /$ app.1989.070371213

[17] Matsumoto A., Hasegawa K., Fukuda A.: Studies on modified phenolic resin. Iv: Properties of phenolic resin modified with 4-hydroxyphenyl- maleimide $/ n$ butylacrylate copolymers. Polymer International, 30, 65-72 (1993). DOI: $10.1002 /$ pi.4990300110

[18] Kamon T., Saito K., Miwa Y. Saeki K.: Dynamic mechanical analysis of diamine cured epoxy resin (in Japanese). Kobunshi Kagaku, 30, 279-282 (1973).

DOI: $10.1295 /$ koron 1944.30.279

[19] Choi H., Chung I. S., Hong K., Park C. E., Kim S. Y.: Soluble polyimides from unsymmetrical diamine containing benzimidazole ring and trifluoromethyl pendent group. Polymer, 49, 2644-2649 (2008).

DOI: $10.1016 /$ j.polymer.2008.04.019 